\section{No moda. Hacia el Ecodiseño del vestir}

Paola Cirelli ${ }^{(1)}$

Resumen: Nos encontramos en un punto de inflexión en la historia del sistema de moda, afianzado en 1850. Han pasado muchos sucesos y la moda ha sido protagonista. Hace solo 30 años el Diseño llega a la moda, a través de la Universidad, creando carreras específicas, donde comenzaría su transformación, poco a poco, con pequeños pasos, a partir de acciones individuales, que los profesionales del diseño de indumentaria / moda, realizan en pos de una mejora del sector. El año 2020, ha sido un momento histórico de este sistema. El mundo entero ha visto las consecuencias de llevar al extremo esta industria y este sistema que no para y que se denuncia hace años. ¿Podremos construir un nuevo sistema? ¿Qué elementos son los que desarrolla esta moda, desde hace más de 150 años y se siguen sin cuestionar? ¿Puede el diseño, traernos luz a esta práctica y mejorarla? Los consumidores, diseñadores y la educación, son la clave de este cambio.

Palabras clave: Moda - diseño - educación - sistema de moda - sostenibilidad.

[Resúmenes en inglés y portugués en la página 134]

${ }^{(*)}$ Paola Cirelli es diseñadora de indumentaria por la Universidad de Buenos Aires. Máster en Branding por Pompeu Fabra-Elisava, Barcelona. Dirige su estudio Fashion Design Thinking desde hace catorce años, donde desarrolla marcas sostenibles de indumentaria. Fue docente UBA, UP, UNT, UNER y varias instituciones en Argentina. Actualmente es profesora en LCI y Elisava, Barcelona, en varios másteres y en grado. Coautora de Buenos Aires es Tendencia, diseño de indumentaria en la era digital, editado en el 2012 por Random House Mondadori, Sudamericana.info@fashiondesignthinking.com

\title{
Introducción
}

Para entender el complejo sistema de moda, y la relación con el diseño, tomaremos los siguientes puntos:

- La construcción del sistema de moda, dictaminada por las casas de lujo (europeas en su mayoría), a partir del 1850. 
- El cambio estacional de las propuestas de moda que, a fines del siglo XX, se fue acelerando hasta considerarlo fast fashion.

- El fast fashion, ha generado que los tiempos de diseño y producción, se han acortado, por lo tanto, muchas marcas se someten a la copia de ideas impuestas desde Europa y Estados Unidos, como una verdad a seguir, para asegurarse la venta.

- Cada colección, de las principales casas de alta costura, de Europa o Estados Unidos son visualizadas gracias a la digitalidad. Consideradas como únicos referentes a seguir, estas ideas se las trasladan a todo el mundo, unificando criterios. Por ejemplo, en Argentina se copia la temporada pasada europea, como si las estaciones tuvieran un lugar desde donde partir, y la idiosincrasia local, cayera en un olvido.

- En los años 90, las marcas tomaron la decisión de vender intangibles, deshaciéndose de las fábricas propias, para contratar a terceros, desligándose de responsabilidades. Esto permite que las inversiones se centren en las publicidades para construir más la imagen de marca. Esto también obnubila a las personas, conectando emocionalmente con las marcas y olvidándose el valor del producto, por sobre el valor de lo intangible. Las marcas aprovechan ese aluvión de nuevos consumidores, para oscurecer el trasfondo de la fabricación de los productos. Ya nadie sabe dónde se produce, pero tampoco importa.

- Se traslada la producción a países donde las leyes laborales y derechos humanos casi no existen. Permitiendo a las marcas mayor rentabilidad; bajo coste, precio alto de venta.

- Otro punto para analizar del fast fashion, son los tiempos de entregas de la producción. Esto genera que muchos talleres, sometan a sus trabajadores a jornadas interminables, en algunos casos, incluyendo noches enteras, produciendo graves problemas de salud, incluso hasta la muerte (Klein, 2005).

- La rapidez de todo este proceso conlleva, además, una mayor cantidad de materia prima y rápido circuito de renovación de estos recursos. Por lo tanto, la explotación agrícola y ganadera es indiscriminada, quitando recursos al planeta sin tiempos de recupero, para luego, además, generar desechos como basura, propia del desarrollo productivo. O, para peor, en algunos casos son incinerados miles y miles de productos.

- "Para saber el color de temporada, hay que mirar los ríos de China".

- La obsolescencia programada de los productos. Creados para morir.

- Los diseñadores preparados por las universidades y escuelas, se encuentran con un sistema que no permite la creación, sino el seguimiento de estas pautas planteadas por la moda y apoyadas por una economía que no tiene reparos. Generando frustración, ya que se debe alimentar la maquinaria sin preguntar.

- Los consumidores, más conscientes tras el Covid-19, empiezan a mover la vara con la que antes se medía la moda. Por lo menos informándose, cuestionando, y en algunos casos tomando decisiones de cambio.

- Treinta y dos años han pasado desde la creación de la Carreras de Diseño de indumentaria, en la Universidad de Buenos Aires (1989) Esto ha generado muchos profesionales con ansia de cambio.

"En estos momentos se necesitan pensadores de diseño, que mejoren nuestro entorno social, económico, medioambiental, y que ayuden no solo a resolver problemas, sino que sean visionarios de nuevas oportunidades" (Serrano Ortega y Blazquez Ceballos, 2015). 


\section{La moda, una construcción social}

La moda está entretejida en nuestro día a día. Entrelazada sin discriminar, en todo aquello que miramos, compramos, deseamos. Sólo una mirada atenta, puede disuadir si es copiado, si es tendencia, si es diseño, o si es todo eso, en pequeñas proporciones.

Es hora de separar cada elemento para analizarlo, cuestionarlo y reconstruirlo. Así, nos encontramos en este inicio del 2021, con una industria que no se puede sostener más como la conocemos, y en un sistema de moda, que deberíamos desarmar para armar con otras premisas. Es necesario, es urgente.

Para identificar los inicios de este sistema, podemos decir que este fenómeno social, coincide con el nacimiento de las sociedades democráticas burguesas de Occidente, en el siglo XIX (Monneyron, 2006). En su libro 50 preguntas sobre la moda, Frédéric Monneryron incorpora un elemento clave en el desarrollo de la moda; las publicaciones de moda. Estas han tenido un papel preponderante, ya que actuaron como motor para propulsar, definir y afianzar la moda del momento. En 1829 aparece La Mode fundada por Emile de Gardin. La Mode se presenta como periódico aristocrático, donde afirma que una mujer elegante no borda su propio delantal, y sí debe cambiarse su ropa, tres veces al día (Monneyron).

Hasta mediados del siglo XIX dos personajes construyen la moda de una forma particular, sastres y modistas. Las prendas no tenían un mayor recambio, y todo dependía del gusto del cliente. Hasta que en 1850 aparece la figura del inglés Charles Frederik Worth, quien permite la aparición de la alta costura y el inicio del sistema de moda. Presentaba sus creaciones mostradas por modelos a clientas. Así comienza a dictar de esta manera la moda, que por primera vez se ha independizado definitivamente del poder político y de la vida pública. Ahora sí, la moda se ofrece como arte desde un creativo hacia las audiencias, definiendo así colores, texturas y formas.

La alta costura se instala en el imaginario colectivo como el lujo, inalcanzable, e impone ciertas reglas. Acceden solo algunos, el resto, entra en la llamada "ley de imitación".

Para Gabriel de Tarde; "La ley de la imitación (1890) sitúa la imitación en el principio mismo de toda actividad humana y concibe la sociedad como un conjunto de individuos que se imitan entre sî" (Monneyron, 2006). Y también indica que, las clases inferiores de las sociedades son las que copian a las clases superiores, en cuestión de ropa, modales, lenguaje, etc. Esto produce que la moda también se mueva constantemente. La clase social alta al verse imitada por la clase social inferior necesita moverse para colocarse en el nivel superior y seguir diferenciándose.

Otro punto importante en la historia de la moda es la aparición del prêt-a-pòrter (1955) propuesta por muchas de las marcas de alta costura, para acercarse a mayor cantidad de público. El público joven, como consumidor, comienza a aparecer en los 50 y se refuerza en las siguientes décadas 1960-70, iniciando así la moda joven y con ello un nuevo lenguaje, el de imponerse a los mayores a través del vestir.

Estos cambios bastante profundos, se dan en espacios de tiempo mucho más largos de los que hoy entendemos.

Hasta que en el año 1973 se reestructura por la crisis del petróleo, acelerando de forma exagerada el sistema de moda (Delgado Luque y Gardetti, 2019). En 1985 aparece el grupo Inditex, entre las marcas creadas, está su más conocida Zara. 
El verdadero punto de inflexión en la historia de la moda la propició Amancio Ortega a partir de la creación del imperio Inditex. El fenómeno Zara y las redes sociales han transformado absolutamente la moda y también el papel de los diseñadores. A partir de ese momento cambiaron las reglas del juego. Zara lo cambió todo; no solo el modelo de consumo, sino también la difusión (Delgado Luque y Gardetti, 2019).

Uno de los puntos a destacar, es que los trabajadores de Zara asistían a desfiles de grandes casas de moda, para copiar y reproducir en muy poco tiempo, y a bajo coste, modelos de pasarela.

Hoy siguen apareciendo denuncias de copias.

Un caso que se llevó a juicio, fue el de la marca Rains. "Zara ha sido considerada culpable por copiar dos de los modelos de chubasqueros o parcas de la marca textil danesa Rains"1.

La moda es un sistema de regulación social de naturaleza propia, cuyo objetivo es la innovación, se convierte en un marcapasos fundamental para el cambio social, en cuyo desarrollo la costumbre y la tradición estilística cumplen su función y se abren al mismo tiempo a nuevas posibilidades (Delgado Luque y Gardetti, 2019).

Simmel además ya decía en su texto "La moda” (1895) “...el individuo se libra del tormento de decidir y queda convertido en criatura de un grupo, en receptáculo de contenidos sociales" (Monneyron, 2006).

Cabe agregar que, desde su nacimiento, el hecho de sistematizar la moda consiste básicamente en una herramienta de control sobre las multitudes, sirviendo para establecer parámetros y comportamientos a través de la uniformidad de colores, formas, texturas, tejidos, incluso lugares, formas de hablar o cómo llevar el cabello o el uso de determinadas marcas. La competencia entre las personas se fue dando a partir de entonces porque a través de ciertas modas se reflejaba un poder económico. Es decir, comenzó a suceder el fenómeno de distinción e imitación, ya que nuestra libertad está condicionada por la realidad y esto forma parte del lenguaje de la moda (Delgado Luque y Gardetti, 2019).

El hecho de seguir los dictámenes de moda, de un sistema impuesto hace 150 años, dirigida por intereses económicos empujados por empresas textiles, grandes marcas de lujo, y revistas de moda, que tiene como objetivo alentar a las personas a seguirla, sin pensar ni detenerse a reflexionar si realmente es algo que desea, que necesita o funciona, es algo que a priori, podríamos desconfiar. 


\subsection{Problemáticas derivadas del sistema}

Este engranaje empuja a los consumidores a seguir parámetros alocados, incitando a cambiar su guardarropa varias veces en un año. El fast fashion genera entre 6 u 8 colecciones anuales. Este nivel de preponderancia en lo visual sirve para cubrir una pulsión del ser humano que es la compra desmedida, como parte de la conformación de la identidad, donde las personas en este fanatismo de pertenecer buscan el precio más bajo por sobre cualquier otro aspecto del producto. Así es fácil descartar con la etiqueta puesta, porque ha costado menos que un bocadillo. Un titular en el New York Times decía “¿Cómo es posible que una prenda sea más barata que un bocadillo? ¿Cómo puede costar un par de euros un producto que necesita ser sembrado, cultivado, cosechado, peinado, hilado, tejido, cortado y cosido, terminado, impreso, etiquetado, empaquetado y transportado?”2.

Muchas marcas sostenibles, ya rechazan los tiempos de las rebajas, los “Black Friday" para darle batalla a las marcas del fast fashion, que liquidan grandes cantidades de prendas, a precios irrisorios, y generando compulsión de compra sin necesidad. Además, estas marcas sostenibles, defienden la construcción de sus precios, ya que tienen costos de materia prima y fabricación más justos, por lo tanto, distan de las marcas fast fashion ${ }^{3}$.

Dos de los grandes problemas que encontramos derivados del sistema de moda, son contaminación medioambiental y explotación de personas por trabajo esclavo.

Otro de las graves implicaciones de la moda con el medio ambiente, es que las grandes marcas, de lujo y no tan de lujo, incineran cientos y cientos de prendas cada temporada ${ }^{4}$. Según el portal Moda sostenible Barcelona "A través del hashtag \#RetailMadeMe, TikTok se convierte en el escaparate de marcas que obligan a sus empleados a destruir o deshacerse de artículos perfectamente utilizables".

Muchas prendas arrojadas a la basura están con sus etiquetas originales, sin usar. Es más barato tirar, que comprar nuevamente. Hay miles y miles de toneladas de prendas en circulación sin uso, que se denominan basura.

\section{Diseño y Universidad}

El diseño irrumpe en la moda para transformarla. A finales de 1980, se crean en el mundo las carreras de diseño. Hasta ese momento, las escuelas de moda enseñaban desde el desarrollo de patronaje y la creatividad individual de un artista. Entonces podíamos encontrar modistos, sastres, creativos y copiadores.

Al desarrollarse las carreras de Diseño, con una profunda mirada, desde lo comunicacional, basado en la metodología proyectual y pensamiento de diseño, se propone un cambio vertiginoso. Centrar el eje en observar los problemas de las personas y la relación del diseño con la industria. Por lo tanto, se analizan las formas de producción. Es decir que "el diseño trabaja para y con la industria", así lo decía el arquitecto Ricardo Blanco, primer director de la Carrera de Diseño de Indumentaria en la Facultad de Arquitectura, Diseño y Urbanismo de la Universidad de Buenos Aires. Y es interesante destacar que en los inicios de la carrera en FADU de UBA, los perfiles profesionales de los que conformaban la plan- 
tilla docente en esos primeros años, no todos tenían relación con la industria del vestir, ni con la moda. Provenían de la arquitectura, en su gran mayoría, del arte, de la sociología. Por eso al seleccionar el nombre para esta nueva carrera, la socióloga Susana Saulquin, parte del comité de creación de la Carrera, insistió en denominarlo Diseño de Indumentaria. "Como es habitual, definir o nombrar limita; quedó en ese acto establecida la diferencia entre hacer "diseño de indumentaria" -que pueda luego o no transformarse en moda- o hacer "diseño de moda" (Chiesa y otras, 2012).

Antes de 1989, el diseño no era parte de la moda. El diseño aterriza en la moda para cargarla de sentido, transformarla y, de este modo, resolver los problemas de las personas. Pero también para reducir el impacto ambiental, abordar los diversos y cambiantes factores económicos, entender los contextos culturales, las problemáticas industriales y productivas y otros puntos donde las metodologías proyectuales tienen un rol clave (Chiesa y otras, 2012).

Así durante los últimos 30 años se han formado a diseñadores, que pueden o no pensar en moda. Diseñadores que pueden o no, crear moda. No es un requerimiento del diseñador, al igual que sucede con otras disciplinas del Diseño. Por ejemplo, una tipografía puede estar de moda, mientras convive con otras más de vanguardia.

El diseñador también refleja el momento coyuntural en sus productos, ya que su mirada es muy perceptiva sobre el entorno, pero fundamentalmente sobre los cambios sociales. $\mathrm{Su}$ producto es estético, equilibrado, responde funcionalmente, está conectado con la persona desde su antropometría, su vida diaria, sus movimientos, empatiza, entiende sus sentimientos. Y por otro lado resuelve problemáticas técnicas, entendiendo las limitaciones de la industria, complejidades de materiales, y creación de nuevos materiales. Disminuye los impactos medioambientales, porque el entorno lo integra con su mirada holística. Todo es diseño.

En cambio, la moda está enfocada netamente en lo visual, en responder a lo masivo y que logre el impacto en muchas personas. No siempre se tiene en cuenta lo funcional, lo técnico y lo medioambiental. Vemos miles de prendas de la moda, y particularmente de marcas de fast fashion, que se descosen, se estropea el tejido con un solo lavado, que se deforma con un solo uso, y que además somete a la persona a usos no saludables, como vemos en los casos de denim que dejan marcas en la piel. Muchas prendas no están pensadas, no están diseñadas. Se copian porque alguien dijo que se usa.

Los diseñadores de indumentaria desarrollan prendas que las personas necesitan utilizar con su cuerpo, apoyadas en su piel. Y también resolver necesidades comunicacionales, estéticas, simbólicas, ergonómicas, económicas y de ocasiones de uso. Por lo tanto, el diseño llega a la moda para ampliar los horizontes del pensamiento crítico orientado hacia un abordaje integral de un cuerpo que se mueve en el espacio y en el marco de una sociedad (Cirelli, 2018). 


\section{1. ¿Cómo se piensa el diseño sin moda?}

La respuesta es muy simple, con metodología proyectual y pensamiento de diseño.

Desde los años 60, varios teóricos han desarrollado la metodología que hoy conocemos. Una de las más populares estudiadas en la asignatura de Diseño, es la de Bruno Munari, que aparece en su libro ¿Cómo nacen los objetos? (Munari, 1983). Allí realiza un desglose desde el problema hasta la solución y todos los pasos que se encuentran a partir de abrir inteligentemente estos conceptos. A grandes rasgos, podemos entender la metodología a través de tres fases. Fase analítica, fase creativa y fase de verificación. Siendo la primera la fundamental, para lograr el cometido final. Es decir que los diseñadores esquematizan mentalmente el abordaje de un problema, pudiéndose ver desde muchas perspectivas a partir de la creatividad, y de una importante pregunta, ¿Que pasa sí?

En el año 2009 Tim Brown Ceo de Ideo, en una charla ${ }^{5}$ que luego ha sido reproducida por miles, y sintetizada en su libro Change by Design (Brown, 2020), proponía al pensamiento de diseño, no sólo para diseñar objetos o servicios, sino para resolver problemas sociales. Y desde allí el diseño entró en áreas donde antes nunca había estado, como ONG, medicina, empresarias, ingeniería, etc. El diseño entonces le aportaría a estas disciplinas, mayor apertura a la hora de encarar un proyecto y fundamentalmente poner al hombre en el centro de todo. Human centered Design ${ }^{6}$.

Cuando hablamos de la relación del diseño con la industria, es importante entender el complejo engranaje que la producción de indumentaria conlleva.

En el año 2008 comencé a dictar clases en la Universidad de Buenos Aires, para la carrera Diseño de indumentaria en la materia Técnicas de Producción de indumentaria. Y allí, ante la falta de imágenes de talleres, fotos de maquinarias y talleristas trabajando que hasta ese momento no se habían mostrado a los alumnos, salí a buscar imperiosamente aquello oculto por la ciudad. En mi caso personal, siendo estudiante, cuando consultaba a las profesoras sobre talleres, siempre encontraba puertas cerradas, era un tema secreto. No entendía en ese momento cuál era el problema, que lamentablemente no tardé en hallar. Como docente sentí la necesidad de mostrar este mundo real a los alumnos y me propuse relevar talleres, sacar fotos e invitar a los fabricantes a dar charlas en la Universidad. No fue fácil acceder a talleres legales. Y en esa búsqueda insistente también me encontré con muchos casos de esclavitud, de gente que me contaba sus casos y de conocer a primera mano el taller La Alameda ${ }^{7}$, con la que tuve la suerte de trabajar varios años. La Alameda es una cooperativa de trabajo, conformada mayormente, por personas rescatadas de la esclavitud textil.

Es decir que la visualización, para la educación en el diseño de indumentaria de las condiciones laborales de toda la cadena productiva, era y es fundamental para concienciar a los futuros diseñadores. Como diseñadores en una empresa, somos los principales generadores de colecciones, ya sean copiadas (por pedido expreso de la empresa) o generada. Por tanto, somos responsables de cómo nuestras ideas luego se convierten en producto. Esta manera de pensar de forma integral es otro de los cambios que propone el DISEÑO a la moda.

Pero el sistema está tan instalado, en la lógica de crear moda, imperante por ciertas marcas, que es complejo el trabajo del diseñador. En el 2018 realicé una encuesta a 80 diseñado- 
res de indumentaria que estuviesen trabajando en empresas de Argentina. En la encuesta reflejaba el malestar con su trabajo. En una de las preguntas ¿Cómo te sentís respecto a la industria siendo diseñad@r de indumentaria/moda? La mayoría reflejaba malestar, decepción, frustración, indignación, poco valorado. En la mayoría de estas empresas, el diseñador copia, no diseña ${ }^{8}$. Cabe aclarar, además, que en muchos casos los diseñadores sufren maltrato dentro de la empresa, y sus sueldos no se comparan con los de otras disciplinas, son radicalmente más bajos.

El sistema de moda se alimenta, se desarrolla, crece y muere cada menos de 6 meses. Esto conlleva producir millones y millones de prendas a costos bajos. Incluso para las marcas de lujo, que, para no ser descubiertas sobre el origen de su producción, ensamblan sus productos en el país de origen, colocando etiquetas con el famoso, "made in France" o Italy.

Incluso las marcas de moda más elevadas participan en la explotación de los trabajadores más vulnerables en sus cadenas de suministro. Marcas de lujo como Dior y Saint Laurent a menudo recurren a subcontratistas en la India para la producción de intrincados bordados y adornos a costos más bajos. Los artesanos altamente calificados contratados para realizar el trabajo reciben poco crédito o dinero por su trabajo?.

Las carreras de Diseño propone un cambio respecto a la visión de cómo la moda se piensa se aborda, y se construye.

Debemos tener en cuenta que, en el desarrollo del currículo de los 4 años de una carrera, se estudia la historia de la moda, pero las asignaturas con más peso son las que potencian el pensamiento proyectual, pensamiento de diseño. Más o menos estructurado, inicia con un problema a resolver.

Por ejemplo, en la Universidad de Buenos Aires se guía a los alumnos a NO mirar moda. Mi formación en diseño, a principios del 2000, se basaba en analizar a los diseñadores que habían generado un cambio, diferente a la moda del momento.

¿Porque mirar la moda si eso ya es pasado? Porque para diseñar, además de entender el contexto, se debe cuestionar lo establecido. Esa también es una característica del Diseño. A la moda se sigue por imitación, el diseño tiene otra trayectoria.

Para generar una disrupción y proponer algo nuevo, debíamos mirar a diseñadores que iban por vías no convencionales, que no tienen una gran aceptación en la población, considerados más nicho, y no masivo.

¿Por qué configurar nuestra mente de diseño con moda, si eso ya es masivo?

En la materia diseño, especialmente había una mirada sobre los grupos de diseñadores disruptivos, como los japoneses ${ }^{10}$, los belgas, los ingleses y los brasileños. Nombres como Dries van Noten, Ann Demeulemeester, Dirk Van Saene, Walter Van Beirendonck, Veronique Branquinho, Gareth Pugh, Raf Simons ${ }^{11}$

Diseñadores brasileños como Alexandre Herchcovitch, Reinaldo Lourenço, Glória Coelho, Pedro Lourenço, Osklen.

Los japoneses: Rei Kawakubo. Yohji Yamamoto, Issey Miyake.

Diseñadores Ingleses como Vivienne Westwood, Alexander Mc Queen, Stella Mc Cartney. John Galliano, Hussein Chalayan, Matthew Williamson, Gareth Pugh, Rick Owens. 
Todos grandes diseñadores que no seguían, ni siguen contemplando las casas de alta costura para desarrollar sus diseños. Sino tienen una búsqueda más disruptiva, y hasta desarrollan nuevas metodologías de patrones como es el caso de Iris Van Herper.

\subsection{Estudiantes de diseño, segunda década del siglo XXI}

En los años de docente he visto infinidad de proyectos, no solo de diseño, de branding, de procesos creativos y de método de diseño. Cada uno de ellos expone el momento coyuntural vivido. La docencia me permite vislumbrar cambios generacionales y percibir los temas latentes. Desde el 2008 hasta hoy, los proyectos de los jóvenes se han posicionado cada vez más en pensamientos críticos, y de profundidad.

Por ejemplo, en los cursos que dicto en LCI (Escuela de diseño en Barcelona) ${ }^{12}$, sobre pensamiento de diseño (Design thinking) y metodología proyectual en segundo año, y en Máster de diseño de Moda, propongo como punto de inicio para el desarrollo de un proyecto, seleccionar un tema. A veces el ejercicio ya tiene un briefing, o simplemente es el desarrollo de una colección de mujer / hombre.

$\mathrm{Al}$ seleccionar el tema, previo desarrollo de ejercicios como Mind map, y escribir sobre ello, los alumnos buscan algo que los moviliza. Muchas veces son temas que les hacen ruido, que les apasiona, que están leyendo, mirando, escuchando o investigando. Es interesante ver las miradas de jóvenes que en muchos casos no llegan a los 20 años, con preocupaciones que van desde el arte, la arquitectura, la ecología, el género, las identidades sexuales, la música, lo psicológico, la fotografía, artistas contemporáneos visuales, temas como el feminismo o incluso la revolución, el punk o la familia. Todos son temas que se utilizarán para realizar diseños. Desde estos temas, apoyados por imágenes y textos, los alumnos ya captan el momento coyuntural. Por lo tanto, es muy actual su percepción. Entonces allí comienza la aventura del diseño, analizar las imágenes a partir de operaciones morfológicas, les explico sobre fundamentos del diseño, del libro de W. Wong, y extraen así, texturas, colores, textiles, sensaciones, un mensaje que se denomina Idea Rectora. Identifican un plan de necesidades del grupo al que van a diseñar. Plantean luego un posible patronaje. Como todos estos elementos, los alumnos arman un Sketchbook, que forma parte de la primera fase Analítica del diseño, y que luego seguirá su curso, hacia las otras dos fases, creatividad y verificación o desarrollo.

Jóvenes con gran sensibilidad, preocupados por la sostenibilidad. Son jóvenes obviamente conectados a las redes, ya que son nativos digitales, pero también cuestionan tanto tiempo en pantalla y necesitan el contacto con la naturaleza y las personas.

\subsection{Diseño en el mercado}

En las marcas más pequeñas, sin la cobertura periodística que puede tener una marca de alta costura, encontramos muchas con una estética, y desarrollo de diseño que es sorprendente. No sólo resuelven problemas que las personas tenemos, sino que además desarrollan productos integrando comunidades y partiendo de economía circular como es el 
caso de Indianes ${ }^{13}$, marca de Barcelona de zapatos, (ambos diseñadores de producto) que proponen zapatillas, creadas con fibra del banano mezclada con algodón. Tejen el patrón final (un 3D) sin necesidad de desperdicio. Además, contribuyen a la economía circular y apoyo a pequeñas comunidades de Colombia, ya que las fibras del banano son extras de la industria y el producto logra además ser biodegradable.

Otro ejemplo lo vemos en la joven diseñadora argentina afianzada en Holanda, Juliana García Bello ${ }^{14}$, ganadora del premio Redress Design Award 2020. Juliana trabaja con donaciones de los vecinos. Genera una colección atípica, ya que no puede pensarla con anterioridad. Una vez que el material llega el diseño cobra vida. Diseño vanguardista y a la vez atemporal. Una colección en base a la economía circular.

En una charla para Maldita Moda club ${ }^{15}$ con Caro Bessaso que tiene su marca en Buenos Aires, comentábamos el tema de los colores de moda. Preguntas como ¿Qué color se usa esta temporada? ¡iY ella me decía “es tan irrelevante!!”. El caso de Dam, también se puede analizar como Diseño atemporal y de vanguardia, fuera de la moda. Caro diseña sus prendas de tejidos traídos de diferentes países y siguiendo su propia idiosincrasia. Generando una marca de indumentaria muy particular. No es moda, no es masiva.

La moda se masifica, el diseño no necesariamente llega a ser moda.

El diseño de indumentaria puede o no contener moda masiva.

\subsection{Ecodiseño}

En los últimos años, se ha colado entre las currículas el ecodiseño ${ }^{16}$. Tiene como principal objetivo, que, en la génesis del desarrollo de una idea, se cumpla la mayoría de los principios del Ecodiseño. Algunos puntos importantes son ${ }^{17}$ :

1. Selección de materiales de bajo impacto.

2. Reducción de la cantidad de material usado.

3. Selección de técnicas de producción ambientalmente eficientes.

4. Selección de técnicas de distribución ambientalmente eficientes.

5. Reducción del impacto ambiental en la fase de utilización.

6. Optimización del Ciclo de Vida.

7. Optimización del sistema de Fin de Vida.

8. Optimizar la función (nuevas ideas de producto) $)^{18}$.

Una marca que cumple con la mayoría de los puntos del Ecodiseño es Thinking $\mathrm{Mu}^{19}$ (Barcelona). Desde el 2006 se han conectado con la agricultura ecológica, principalmente con Perú. Utilizan materiales certificados, fibras recicladas, y talleres de trabajo justo. Además, desarrollan un proyecto llamado Trash, donde a partir de las prendas que sus clientes ya no utilizan y entregan a la marca, generan tejidos reciclados, y con retales de otras temporadas, desarrollan prendas. Es decir que el circuito lo completan, dando valor a algo que ya no está en uso.

Otro caso interesante es el de la marca Circoolar ${ }^{20}$, que desarrolla ropa de trabajo a partir de materiales orgánicos o reciclados. Plantean el ciclo completo de economía circular. Una 
vez que los trabajadores finalizan el uso de las prendas, Circoolar las recoge para luego volverlas a meter en el circuito del reciclaje.

En este punto es importante entender que cuando se diseña, la prenda debe estar preparada para la circularidad. Por ejemplo, es necesario elegir materiales $100 \%$ de una fibra, o mezclas similares. Porque cuando esa prenda se desarme en fibra nuevamente, para volver a tejer, la separación de la composición no sea imposible. Otro punto a tener en cuenta es que no sea complejo el despiece de esa prenda, porque este paso puede demorar muchas horas. Costuras, botones, apliques, bordados, etc. El ecodiseño debe estar presente en la génesis de nuestro diseño, para lograr así, que la muerte de esa prenda sea el inicio de una fibra. Como siempre se dice "lo más sostenible es aquello que ya está producido". Ya que no necesita de energía nuevamente para el desarrollo.

"Solo el 15\% del textil termina, por lo tanto, en algún proceso de reciclaje. La mayor parte, el $12 \%$, se reutiliza para confeccionar otros productos textiles (relleno de colchones, paños de limpieza, alfombras, materiales de aislamiento o alfombrillas de los coches), un $2 \%$ se pierde durante la recogida o el procesado y, finalmente, ¡un $1 \%$ se convierte en nuevas ropas! Un 1\% que incluye los retales que sobran a la hora de la fabricación. Si sólo hablásemos de la ropa como tal, ropa reciclada en ropa, el porcentaje se reduce al $0,1 \%{ }^{21}$.

\subsection{Diseño distribuido}

El nuevo desafío de las marcas de diseño sostenibles es generar el mínimo impacto. Entre los diferentes puntos, se evalúa la huella de carbono producida por los envíos de productos a todo el mundo, a través de barcos y aviones.

Por lo que, en los últimos años, se está generando a nivel internacional, un movimiento llamado Diseño Distribuido. Esto permite que las marcas, vendan además de productos, servicios de moldes, patrones, y explicaciones de cómo se conforman sus diseños para que en otros países se produzcan sin la necesidad de envíos. Podría ser una especie de franquicia, con la ventaja que la materia prima saldría de la zona donde se encuentra esa marca y mano de obra local.

Un ejemplo es la startup barcelonés de Gafas llamada Fos Barcelona ${ }^{22}$. Esta marca sostenible, realiza diferentes diseños, a partir del reciclaje de bolsas de plásticos. Además, una vez desechado el producto por parte del cliente, se puede desarmar fácilmente para volverlo a integrar a la cadena productiva (Ecodiseño). Otro servicio propuesto es el Diseño Distribuido. En su web se explica:

Moldes para fabricar gafas de sol en tu ecosistema. Consiste en dos moldes: Molde de montura y molde de patillas. Los moldes se fabrican en $\mathrm{Al}$ 7075, están acabados para borrar todos los pasos de herramienta y ofrecen un acabado de superficie mate...El molde incluye:

- Documentación sobre cómo usar el molde.

- Documentación sobre cómo prolongar la vida del molde.

- Soporte post venta.

- 10 horas de consultoría a mitad de precio. 
Esta práctica aún no está extendida en el diseño, pero promete ser un movimiento que cada año cobra fuerza.

\section{Consumidor consciente}

Uno de los mayores aprendizajes que esta Pandemia a nivel mundial nos ha traído, es sobre todo el cuidado de la salud. El primer impacto que recibimos fueron los cambios en torno a nuestra movilidad. Confinados 24 horas en nuestras casas, con cuidados sobre cómo salir a la calle y conectados a una pantalla para el trabajo y las relaciones sociales, nos generó un cambio sobre el consumo. Al menos en ese tiempo, todo empezó a mirarse bajo lupa. Las noticias sobre los cambios medioambientales denunciados hace años, eran moneda corriente. Esto que vivimos es una consecuencia, no un hecho aislado, eso ya todos lo sabemos. Vimos en el 2019, expuestos por las redes sociales, muchos más datos a través del aporte de Greta Thunberg ${ }^{23}$. Una joven de tan solo 16 años que ha movilizado a miles de personas a protestar por el cambio climático.

"Si un solo virus destruye nuestra economía en semanas, es que no estamos pensando a largo plazo".

Algunos datos importantes.

- $\quad 31,1 \%$ de los consumidores europeos está dispuesto a gastar más dinero si los productos son sostenibles, según una encuesta realizada por el Institut Français de la Mode ${ }^{24}$.

- Para el resto de los consumidores de entre 18 y 34 años que no contemplan gastar en productos sostenibles el precio es el principal obstáculo. En ese sentido, la segunda mano se ha convertido en la mejor opción para este tipo de cliente.

- El 30,8\% de los europeos señala que comprará moda de segunda mano en los próximos meses, así como un 44,3\% de consumidores jóvenes.

- El consumo después del Covid-19: el 64,1\% de los europeos comprará moda 'eco'.

- En Europa, el $60 \%$ de los consumidores mirará dónde se ha producido las prendas, y el $58,5 \%$ estarán más dispuestos a comprarla si se ha producido en proximidad.

- El 33,1\% de los consumidores de entre 18 y 34 años sentencia que quieren boicotear aquellos productos fabricados fuera del país local.

- 5 veces. Es el número máximo de veces que nos ponemos, de media, una prenda antes de desecharla, (incluyendo lo de quedarse en el cajón relegada al olvido). De hecho, usamos sólo entre el 30 y el $40 \%$ de la ropa de nuestro armario ${ }^{25}$.

- 100.000 mill. Antes del Covid, un consumidor medio compraba un $60 \%$ de ropa más que hace 10 o 15 años. En el mundo se consumen 100.000 millones de prendas nuevas al año, lo que supone un $400 \%$ más que hace apenas dos décadas ${ }^{26}$.

Estas estadísticas nos muestran un estado aún latente, de cambios de comportamientos para el consumidor, pero cada día se refuerza más. Los consumidores somos más conscientes y entendemos nuestro poder de cambio. Las marcas que ya están desarrollando un 
camino sostenible, o en vías de ir hacia lo sostenible son marcas que serán relevantes para los consumidores. Aquellas que no se han preocupado, poco a poco quedarán en el olvido.

\section{4. ¿Podemos cambiar el sistema de moda?}

Deberíamos pensar en lo que decía Einstein, resolver un problema con las mismas condiciones que la produjeron, es complejo.

En una charla "Enseñar es un arte", Ken Robinson, educador y escritor ${ }^{27}$, reflexionaba sobre cambiar el sistema educativo y decía que la gente a menudo siente que es imposible cambiar el sistema educativo, pero es importante entender que tipo de sistema es. No es un sistema mecánico, ni inerte y no funciona por algoritmos, es un sistema humano, que se lo denomina, sistema adaptativo complejo. Y decía;

Quiere decir que está compuesto por múltiples elementos. Está compuesto por miles de millones de personas, en cientos de miles de instituciones con innumerables intereses, innumerables puntos de interacción entre sí. Está compuesto por innumerables acciones todos los días, y todas están fluctuando...El funcionamiento del sistema, tiene unas características dominantes, pero es un diseño dinámico y vibrante.

Y luego dice, "todos los días se realizan acciones individuales, desde muchos puntos. Por lo tanto, se puede cambiar el sistema, desde dentro del sistema".

De la misma manera, podemos pensar en este gran sistema de moda, como el sistema educativo. El poder del cambio son las acciones individuales, desde dentro del sistema. Para lo cual tenemos TRES claves para el cambio:

1. El diseñador.

2. El consumidor consciente.

3. La EDUCACIÓN que vincula a los dos anteriores.

¿Por qué no se nos enseña sobre cómo comprar desde pequeños? ${ }^{28}$

La educación en los primeros años de vida es fundamental para tener el conocimiento de seleccionar bien qué comprar, y a qué precio. Discriminar aquellos productos de procedencia incierta, de aquella de talleres locales y de materia prima natural de la sintética o artificial.

\section{Conclusiones}

Estamos entrando en la era de diseño consciente del vestir indumentaria, despojado de la moda, tal cual la conocíamos. El sistema está siendo revisado, cada día más a pasos agigantados. Es un sistema que no funciona de manera sostenible, que ha revelado en los 
últimos años, ser uno de los principales responsables de los problemas medioambientales que hoy vivimos y que somete a miles de personas a la esclavitud ${ }^{29}$. Desde marcas de lujo, hasta las marcas fast fashion.

El desafío para la industria es volverse sostenible en todo sentido, necesitamos cambios de políticas de producción, no solo reducir el impacto medioambiental sino tener una regulación de trabajo justo y con sueldos acordes al país donde se venderá este producto ${ }^{30}$.

Debemos cuestionar las huellas que las marcas de moda dejan temporada a temporada y que hasta ahora han operado de manera ciega ante los problemas medioambientales y de esclavitud.

El sistema de moda como lo conocemos debe mutar por completo. Las marcas deben dejar de hacer moda sin sentido, para comenzar a trabajar bajo elementos del diseño consciente, del Ecodiseño, como decía Estel Vilaseca, directora del área de Moda de LCI, Barcelona, en conversación para este texto.

El diseño y la educación son claves para este cambio. En los últimos años, se ha demostrado que se puede cambiar el sistema. Vemos cada día más propuestas y desarrollos tecnológicos que ayudan a este salto. Los diseñadores tienen las herramientas de transformar las empresas, la industria, las propuestas, los productos, la logística y es hora de dejarlos actuar. Diseñar y dejar de seguir (copiar) un sistema instalado en el Siglo XIX. La educación sobre la industria deberá extenderse a toda la población, porque el conocimiento abre caminos, y nos ayuda a tomar mejores decisiones.

El diseñador y el consumidor conscientes, son la clave en el cambio paradigmático de este sistema de moda que nos llevará hacia un modelo más sostenible, de impacto cero, que ya es urgente.

\section{Notas}

1. http://www.peritacionesmga.com/blog/es/culpable-copia-disenos-zara/

2. Moda sostenible Barcelona https://www.modasosteniblebcn.org/

3. Thinking Mu. / Ecoalf / por nombrar algunas marcas españolas importantes en el sector.

4. https://www.mic.com/p/inside-the-tiktok-trend-shaming-corporations-for-destroying -perfectly-good-stuff-

5. Charla de Tim Brown. Ceo de IDEO. https://www.ted.com/talks/tim_brown_designers _think_big?language $=$ es

6. Human center design- https://www.designkit.org/human-centered-design

7. Alameda https://laalameda.wordpress.com/mundo-alameda-la-marca-propia/

8. https://fashiondesignthinking.com/blog-fdt/2019/8/22/es-el-turno-de-los-diseadores -revolucin-en-la-moda

9. https://www.nytimes.com/2020/12/10/opinion/covid-fashion-industry-worker-explo itation.html 
10. https://www.fashionableasia.com/fashion-blog/disenadores-de-moda-japoneses

11. https://www.visitflanders.com/es/temas/moda-belga/historia-de-la-moda-belga/losseis-de-amberes/index.jsp

12. https://www.lcibarcelona.com/

13. https://fashiondesignthinking.com/podcast/2019/10/5/episodio-13-una-historia-inter continental-cuando-el-diseo-une-d

14. https://fashiondesignthinking.com/podcast/2020/9/17/episodio-32

15. https://fashiondesignthinking.com/podcast Podcast Maldita Moda Club.

16. LCI Barcelona. Materia optativa de la Carrera de Diseño de moda.

17. http://www.ecolaningenieria.com/es/ingenieria-ambiental/ecodiseno

18. https:/www.bbva.com/es/que-es-el-ecodiseno-y-por-que-se-va-a-poner-de-moda/

19. Maldita Moda Club entrevista episodio 37. https://fashiondesignthinking.com/pod cast/2021/1/14/episodio-37-thinking-mu-pepe-bargu

20. https://fashiondesignthinking.com/podcast/2020/5/20/episodio-23

21. https://elpais.com/elpais/2020/10/22/alterconsumismo/1603357648_153133.html

22. https://es.fosbarcelona.com/contact

23. https://www.elmundo.es/ciencia-y-salud/ciencia/2021/01/03/5ff0c40dfdddff39448b4 $5 f 2 . h t m l$

24. https://www.modaes.es/back-stage/el-consumo-despues-del-covid-19-el-641-de-loseuropeos-comprara-moda-eco.html

25. https:/www.expansion.com/directivos/2020/06/28/5ef8da7fe5fdea7f638b45al.html

26. Ídem 22.

27. Programa aprendemos juntos del Banco BBVA. https://www.youtube.com/watch?v= WP8WSK-6Pj0 noviembre 2018

28. Conversación para este texto, con Agustin Bossini Pithod diseñador de indumentaria.

29. https://www.bbc.com/mundo/noticias-internacional-55312190

30. En texto palabras de Paola Cirelli https://www.lofficiel.com.ar/moda /moda-pandemia-espana-2021

\section{Referencias bibliográficas}

Brown, T. (2020) Diseñar el cambio. Cómo el design thinking puedes transformar las organizaciones e inspirar la innovación. España: Editorial Empresa Activa.

Cirelli, P. (2018). La segunda revolución de la moda: Los diseñadores. INTI.

Chiesa, M.; Cirelli, P. y Siciliani, P. (2012). Buenos Aires es Tendencia, Diseño de Indumentaria en la Era digital. Buenos Aires: Editorial Sudamericana.

Delgado Luque, M. L. y Gardetti, M.A. (2019). Manual de moda sostenible. Editorial Arcopress.

Klein, N. (2005). No Logo: EL PODER DE LAS MARCAS. Editorial Planeta.

Monneyron, F. (2006). 50 respuestas sobre la moda. Editorial Gustavo Gili.

Munari, B. (1983) ¿Cómo nacen los objetos? Editorial GG. 
Serrano Ortega, M. y Blázquez Ceballos, P. (2015). Design thinking. Lidera el presente. Crea el futuro. Editorial Esic.

\begin{abstract}
We are at a turning point in the history of the fashion system, established in 1850. Many events have happened and fashion has been the protagonist. Only 30 years ago, Design came to fashion, through the University, creating specific careers, where it would begin its transformation, little by little, with small steps, from individual actions, that professionals in clothing / fashion design, carried out in pursuit of an improvement in the sector. The year 2020 has been a historic moment for this system. The whole world has seen the consequences of taking this industry and this system that does not stop and has been denounced for years to the extreme. Can we build a new system? What elements is this fashion developing, for more than 150 years and still without question? Can design bring light to this practice and improve it? Consumers, designers and education are the key to this change.
\end{abstract}

Keywords: Fashion - design - education - fashion system - sustainability.

Resumo: Estamos em um ponto de inflexão na história do sistema de moda, estabelecido em 1850. Muitos eventos aconteceram e a moda tem sido a protagonista. Há apenas 30 anos o Design chegou à moda, através da Universidade, criando carreiras específicas, onde começaria a sua transformação, aos poucos, com pequenos passos, a partir de ações individuais, que profissionais do design de roupas / moda, realizado na busca da melhoria do setor. O ano de 2020 foi um momento histórico para este sistema. O mundo inteiro viu as consequências de levar ao extremo esta indústria e este sistema que não pára e que vem sendo denunciado há anos. Podemos construir um novo sistema? Que elementos esta moda está se desenvolvendo, há mais de 150 anos e ainda sem questionamentos? O design pode trazer luz a esta prática e melhorá-la? Consumidores, designers e educação são a chave para essa mudança.

Palavras chave: Moda - design - educação - sistema de moda - sustentabilidade.

[Las traducciones de los abstracts fueron supervisadas por el autor de cada artículo] 